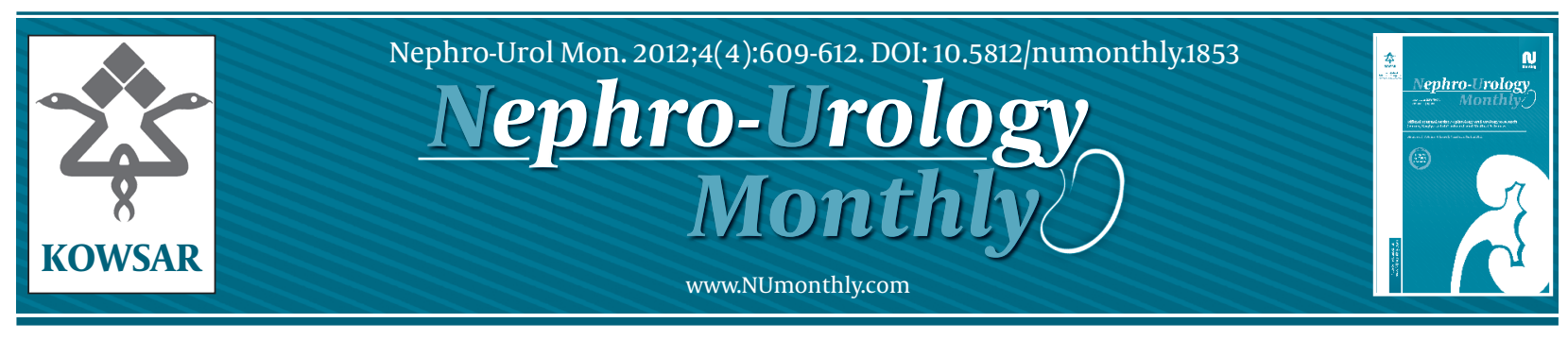

\title{
Different Outcomes of Hypospadias Surgery Between North America, Europe and China: Is Patient Age a Factor?
}

\author{
Wenli Lu ${ }^{1^{*}}$, Yuehong Tao ${ }^{2}$, Amy B.Wisniewski ${ }^{3}$, Dominic Frimberger ${ }^{3}$, Brad P. Kropp ${ }^{3}$ \\ ${ }^{1}$ Department of Pediatrics, Shanghai Ruijin Hospital, Medical School of Shanghai Jiao Tong University, Shanghai, China \\ ${ }^{2}$ Department of Pediatrics, Subei People's Hospital of Jiangsu Province, Jiangsu, China \\ ${ }^{3}$ Department of Urology, University of Oklahoma Health Sciences Center, Oklahoma City, USA
}

\section{A R T I C L E I N F O}

Article type:

Review Article

\section{Article history:}

Received: 10 Jul 2011

Revised: 21Jul 2011

Accepted: 30 Jul 2011

Keywords:

Hypospadias

General Surgery

Outcomes Assessment

\begin{abstract}
A B S T R A C T
Background and Objects: The patient's age at the first hypospadias repair may be an important factor for determining postoperative outcomes. Age at the first procedure differs between Western countries and medical centers in China. This review examines the differences between the incidence of surgical complications and surgical age in boys receiving hypospadias repairs in North America, Europe and China.

Materials and Methods: Literature reports were reviewed in PubMed and WanFang databases using the key terms and phrases; 'hypospadias outcomes', 'complications of hypospadias repair' and 'timing of hypospadias repair'. All peer-reviewed articles published over the past decade (2001-2011) were considered if; a full text was available, the article included age at the first hypospadias procedure and surgical complications.

Results: In total, 16131 patients were reported in 113 papers from North America, Europe and China according to our inclusion criteria. There was a significant difference in age at the first hypospadias surgery $(P<0.0005)$ and in the incidence of complications $(P<$ 0.001 ) between the different global regions investigated, with the earliest surgeries occurring in North American patients. Urethral fistulas were the most common complication reported in all of the regions included in this study.

Conclusions: Fellowship training in pediatric urology could improve surgical outcomes, particularly in young children. Younger children experience fewer complications following hypospadias surgeries, independent of training and access to resources.
\end{abstract}

Published by Kowsar Corp, 2012. cc 3.0.

Implication for health policy/practice/research/medical education:

The present study has evaluated the hypospadias surgery complications in different areas and it can be useful for urologists.

\section{- Please cite this paper as:}

Lu W, Tao Y, Wisniewski AB, Frimberger D, Kropp BP. Different Outcomes of Hypospadias Surgery Between North America, Europe and China: Is Patient Age a Factor? Nephro-Urol Mon.2012;4(4): 609-12. DOI: 10.5812/numonthly.1853

\section{Introduction}

Hypospadias, is a congenital malformation of the male urethra, it is a common birth defect in humans and is purported to be increasing in incidence (1). Variables af- fecting short- and long-term outcomes of hypospadias repair include, but are not limited to; the degree of malformation present, type of surgical procedure employed for the repair, and the training and experience of the sur-

\footnotetext{
* Corresponding author: Wenli Lu, Department of Pediatrics, Shanghai Ruijin Hospital, Medical School of Shanghai Jiao Tong University, Shanghai, China. Tel: +86-4052273185, E-mail:wenli-lu@ouhsc.edu

DOI: $10.5812 /$ numonthly.1853

(C) 2012 Nephrology and Urology Research Center and Baqiyatallah University of Medical Sciences; Published by Kowsar Corp.

This is an Open Access article distributed under the terms of the Creative Commons Attribution License (http://creativecommons.org/licenses/by/3.0), which permits unrestricted use, distribution, and reproduction in any medium, provided the original work is properly cited.
} 
geons performing the repair. Current recommendations from pediatric medical societies in the United States and Europe are to perform hypospadias surgery between 6 and 12 months of age $(2,3)$. In countries such as China hypospadias repair usually occurs in older boys, typically between 4 to 6 years of age, as most surgeons in China do not practice in specialized pediatric facilities nor do they complete pediatric sub-specialty training. This difference in surgical approach is of potential concern, because older patients who receive hypospadias surgery, are more likely to report delayed sexual activity and sexual dissatisfaction (4).

The aim of the current review is to compare the age at first surgery for hypospadias repair and surgical complications (type and incidence) from medical research databases that include peer-reviewed, outcome studies written in English (Pubmed) and Chinese (WanFang). The inclusion of the WanFang database allows for a direct comparison of differences in surgical practice and outcomes between surgeons who train and practice in Western countries versus those in China. Of interest is whether or not a later age at the first surgical procedure is associated with more complications and/or unique types of post-surgical complications following hypospadias repair.

\section{Materials and Methods}

Hypospadias outcome studies from 2001 through 2011 were identified using the Pubmed and WanFang databases. Search terms and phrases included; 'hypospadias outcomes', 'complications of hypospadias repair' and 'timing of hypospadias repair'. Studies that reported the age of patients at the first surgery, degree of hypospadias and type (s) of procedure used were reviewed. When comparing across global regions, for differences in age, complication type and incidence, only first time surgeries were considered.

\section{Results}

A total of 113 studies were selected from North America $(n=30)$, Europe $(n=30)$ and China $(n=53 ; 19$ published in English and 34 published in Chinese; see Table 1). When combined, a total of 16131 patients in these studies received surgical repair for hypospadias. More than 6000 patients presented with distal hypospadias, typically requiring a one-stage procedure to repair. Others presented with a more severe degree of hypospadias that in some cases required a two- or three-stage procedure to repair (see Table 2). One-stage procedures typically included urethroplasty using free inner prepuce or bladder mucosa, TIP, MAGPI, Mathieu, Duckett and Duplay procedures.

\begin{tabular}{lllll}
\hline \multicolumn{5}{l}{ Table 1. Description of Papers and Patients Reviewed } \\
\hline & Paper $(\mathbf{n})$ & Patients $(\mathbf{n})$ & Age at First Surgery (mo) $($ Mean \pm SEM) & Complications No. (\%) \\
\hline North America & 30 & 3797 & $20.60 \pm 2.49$ & $412(10.9)$ \\
Europe & 30 & 3392 & $31.70 \pm 2.85$ & $540(15.9)$ \\
China & 53 & 8942 & $67.14 \pm 4.87$ & $1332(14.9)$ \\
Total & 113 & 16131 & & 2284 \\
\hline
\end{tabular}

\begin{tabular}{|c|c|c|c|c|c|c|c|c|c|}
\hline & Distal & Stage & No. & Proximal & Stage & No. & Severe & Stage & No. \\
\hline \multirow[t]{4}{*}{ North America, $n$} & 2076 & & & 1230 & & & 228 & & \\
\hline & & 1-stage & 2073 & & 1-stage & 978 & & 1-stage & 102 \\
\hline & & Not reported & 3 & & 2-stage & 208 & & 2-stage & 126 \\
\hline & & & & & Not reported & 44 & & Not reported & 0 \\
\hline \multirow[t]{4}{*}{ Europe, $n$} & 2967 & & & 211 & & & 219 & & \\
\hline & & 1-stage & 293 & & 1-stage & 69 & & 1-stage & 93 \\
\hline & & Not reported & 31 & & 2-stage & 122 & & 2-stage & 121 \\
\hline & & & & & Not reported & 20 & & Not reported & 5 \\
\hline \multirow[t]{4}{*}{ China, $\mathrm{n}$} & 1273 & & & 2327 & & & 1656 & & \\
\hline & & 1-stage & 1165 & & 1-stage & 1837 & & 1-stage & 1089 \\
\hline & & Not reported & 108 & & 2-stage & 345 & & 2-stage & 245 \\
\hline & & & & & Not reported & 145 & & Not reported & 322 \\
\hline
\end{tabular}




\begin{tabular}{|c|c|c|c|c|c|}
\hline & & $\mathbf{n}$ & Fistula No.(\%) & Stricture No. (\%) & Glans Dehiscence No. (\%) \\
\hline \multicolumn{6}{|l|}{ North American } \\
\hline & Complication & 412 & $194(5.1)$ & $17(0.4)$ & $24(0.6)$ \\
\hline & No complication & 3385 & & & \\
\hline \multicolumn{6}{|l|}{ Europe } \\
\hline & Complication & 540 & $257(7.6)$ & $34(1.0)$ & $66(1.9)$ \\
\hline & No complication & 2852 & & & \\
\hline \multicolumn{6}{|l|}{ China } \\
\hline & Complication & 1332 & $843(9.4)$ & $15(0.2)$ & $312(3.5)$ \\
\hline & No complication & 7610 & & & \\
\hline
\end{tabular}

As expected, there was a difference in age at the first hypospadias surgery between the different global regions investigated $(F(2)=38.00, P<0.0005)$. North America hypospadias patients typically received their first procedure during the first two years, European patients during the first three years, and Chinese patients during the first five years of life. Many studies reported postoperative complications such as; urethral fistulas, urethral strictures and glans dehiscence (see Table 3). The lowest complication rates were reported by North American investigators and the highest rates occurred among surgeons practicing in China $\left(X^{2}(2)=46.3, P<0.001\right)$. Urethral fistulas were the most common complication reported for all regions, but they were most commonly reported by surgeons in China $\left(X^{2}(3)=68.509, P<0.005\right.$; see Table 3$)$.

\section{Discussion}

In regions of the world where specialized pediatric surgical training exists, age at the first hypospadias procedure occurs in younger patient and is associated with lower complication rates (5-7). This is in line with recommendations for early surgery, prior to 18 months of life or after three years if an earlier opportunity is not possible (3). A possible explanation for the lower complication rates reported by studies from North America and Europe is the difference in training and facilities geared toward pediatric surgery compared with China (5). Specifically, fellowship training in pediatric urology improves surgical outcomes, particularly in young children $(6,7)$. Thus, subspecialty training in pediatric surgery most likely contributes to some of the regional differences reported here. Establishing pediatric surgical training programs in China, similar to those in Europe and North America, would be expected to result in reduced complication rates following hypospadias repairs in these patients.

A second potential explanation for our results is that younger children heal better following surgical procedures, regardless of the surgeon's training and resources. In studies that considered age at surgery within institutions that controlled for surgeon training and experience level, complications were minimized when hypospadias repair was performed in younger patients (8-11).

In summary, early hypospadias surgery may be associated with better long-term outcomes $(2,4)$. Additionally, an inverse relationship exists between age at surgery and memory of the operation, therefore patients who do not remember the earlier procedures, report greater satisfaction with the cosmetic outcome (12). Performing surgeries for hypospadias repair at later ages may predispose patients to a greater likelihood of post-surgical complications, the most common being urethral fistulas. The development of pediatric urology training programs in China may ultimately lead to better outcomes of hypospadias procedures, this could be due in part to greater levels of comfort in treating younger aged patients.

\section{Acknowledgments}

None declared.

\section{Authors' Contribution}

None declared.

\section{Financial Disclosure}

None declared.

\section{Funding/Support}

None declared.

\section{References}

1. Baskin LS. Hypospadias and urethral development. J Urol. 2000;163(3):951-6.

2. Timing of elective surgery on the genitalia of male children with particular reference to the risks, benefits, and psychological effects of surgery and anesthesia. American Academy of Pediatrics. Pediatrics. 1996;97(4):590-4.

3. Manzoni G, Bracka A, Palminteri E, Marrocco G. Hypospadias surgery: when, what and by whom? BJU Int. 2004;94(8):1188-95.

4. Mureau MA, Slijper FM, Slob AK, Verhulst FC. Psychosocial functioning of children, adolescents, and adults following hypospadias surgery: a comparative study.J Pediatr Psychol. 1997;22(3):37187.

5. DeLair SM, Tanaka ST, Yap SA, Kurzrock EA. Training residents in hypospadias repair: variations of involvement. $J$ Urol. 2008;179(3):1102-6. 
6. Horowitz M, Salzhauer E. The 'learning curve' in hypospadias surgery. BJU Int. 2006;97(3):593-6.

7. Frimberger D, Campbell J, Kropp BP. Hypospadias outcome in the first 3 years after completing a pediatric urology fellowship. J Pediatr Urol. 2008;4(4):270-4.

8. Perlmutter AE, Morabito R, Tarry WF. Impact of patient age on distal hypospadias repair: a surgical perspective. Urology. 2006;68(3):648-51.

9. Mureau MA, Slijper FM, Slob AK, Verhulst FC, Nijman RJ. Satisfaction with penile appearance after hypospadias surgery: the pa- tient and surgeon view. J Urol. 1996;155(2):703-6.

10. Dodson JL, Baird AD, Baker LA, Docimo SG, Mathews RI. Outcomes of delayed hypospadias repair: implications for decision making. J Urol. 2007;178(1):278-81.

11. Manzoni G, Bracka A, Palminteri E, Marrocco G. Hypospadias surgery: when, what and by whom? BJU international. 2004;94(8):1188-95.

12. Jones BC, O'Brien M, Chase J, Southwell BR, Hutson JM. Early hypospadias surgery may lead to a better long-term psychosexual outcome. J Urol. 2009;182(4 Suppl):1744-9. 